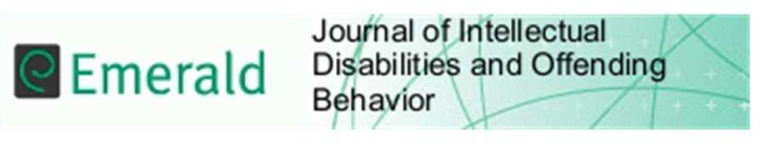

\title{
Outcomes of an Inner City Forensic Intellectual Disability Service
}

\begin{tabular}{|r|l|}
\hline Journal: & Journal of Intellectual Disabilities and Offending Behavior \\
\hline Manuscript ID & JIDOB-08-2017-0016.R1 \\
\hline Manuscript Type: & Research Paper \\
\hline Keywords: & $\begin{array}{l}\text { Intellectual Disability, Reoffending, Reconvictions, Forensic Services, } \\
\text { transforming Care, Community Intellectual Disability Teams }\end{array}$ \\
\hline
\end{tabular}

SCHOLARONE ${ }^{\text {"x }}$

Manuscripts 


\section{Tables}

\section{$\underline{\text { Table } 1}$}

Discharge destination

\begin{tabular}{|l|l|l|l|l|l|l|}
\hline & $\begin{array}{l}\text { Community } \\
\text { assisted } \\
\text { accommodation }\end{array}$ & Family & $\begin{array}{l}\text { High } \\
\text { secure }\end{array}$ & $\begin{array}{l}\text { Other secure } \\
\text { service } \\
\text { (medium } \\
\text { secure) }\end{array}$ & $\begin{array}{l}\text { "Open" } \\
\text { intellectual } \\
\text { disability } \\
\text { service/ } \\
\text { stepdown } \\
\text { facility }\end{array}$ & Prisons \\
\hline Medium & $17(42.5 \%)$ & $3(7.5 \%)$ & $3(7.5 \%)$ & $2(5.0 \%)$ & $2(5.0 \%)$ & $2(5.0 \%)$ \\
\hline Low & $6(15 \%)$ & $1(2.5 \%)$ & $0(0 \%)$ & $2(5.0 \%)$ & $1(2.5 \%)$ & $1(2.5 \%)$ \\
\hline
\end{tabular}

\section{$\underline{\text { Table } 2}$}

\section{Outcomes - time to readmission, reconviction/further alleged offending behaviour}

\begin{tabular}{|l|l|l|l|l|l|l|}
\hline & $\begin{array}{l}\text { Patients } \\
\text { readmitted } \\
\text { to hospital }\end{array}$ & $\begin{array}{l}\text { Readmitted } \\
\text { to secure } \\
\text { care }\end{array}$ & $\begin{array}{l}\text { Readmitted } \\
\text { to non- } \\
\text { secure } \\
\text { care }\end{array}$ & $\begin{array}{l}\text { Time to } \\
\text { readmissio } \\
\text { n (days) }\end{array}$ & $\begin{array}{l}\text { Patients } \\
\text { (allegedly) } \\
\text { reoffended } \\
\text { following } \\
\text { discharge }\end{array}$ & $\begin{array}{l}\text { Time to } \\
\text { (alleged) } \\
\text { reoffending } \\
\text { days }\end{array}$ \\
\hline Overall & $8 / 40(20 \%)$ & 2 & 6 & 871 & 10 & 904.4 \\
\hline $\begin{array}{l}\text { Medium } \\
\text { secure }\end{array}$ & 7 & 1 & 6 & 1002.9 & 9 & 997 \\
\hline $\begin{array}{l}\text { Low } \\
\text { secure }\end{array}$ & 1 & 1 & 0 & 15 & 1 & 72 \\
\hline
\end{tabular}




\section{Table 3}

Patients who were readmitted and those who reoffended - the teams they were under the community

\begin{tabular}{|l|l|l|l|l|}
\hline & CIDS & $\begin{array}{l}\text { Community } \\
\text { Forensic Team }\end{array}$ & $\begin{array}{l}\text { Joint forensic- } \\
\text { CIDS care }\end{array}$ & $\begin{array}{l}\text { Joint CIDS- } \\
\text { general care }\end{array}$ \\
\hline Readmitted & $4(50 \%)$ & $1(16.7 \%)$ & $1(16.7 \%)$ & $2(25 \%)$ \\
\hline Reoffended & $3(50 \%)$ & $1(16.7 \%)$ & $1(16.7 \%)$ & $1(16.7 \%)$ \\
\hline
\end{tabular}




\section{Outcomes of an Inner City Forensic Intellectual Disability Service}

\section{ABSTRACT \\ Introduction}

National policy in England is now directed towards keeping patients with intellectual disability (ID) presenting with forensic problems for time limited treatment. The result is that secure hospital services are expected to work much more proactively to discharge patients to community-based services. However, there is little evidence in recent years on the outcome of discharged patients with ID from secure hospitals. This study describes the outcomes of a patient group discharged from a specialist forensic ID service in London, England.

\section{Method}

This is a descriptive retrospective case note study of patients with ID admitted to and discharged from a secure service with both low and medium secure wards, over a six-year period from 2009 to 2016 . The study examined patient demographic, clinical and outcome variables, including length of stay, pharmacological treatment on admission and discharge, offending history, and readmissions to hospital and re-offending following discharge.

\section{Results}

The study identified 40 male patients, 29 of which were admitted to the medium secure ward. 27 patients $(67.5 \%)$ were discharged into the community with 14 patients having sole support from the community intellectual disability services and four from the community forensic services. $20 \%$ of patients were readmitted within the study period and $22.2 \%$ of patients received further convictions via the Criminal Justice System following discharge.

\section{Conclusion}

This was a complex group of patients with ID discharged into the community with a number at risk of requiring readmission, and of reoffending. Community based services providing for offenders with ID must have sufficient expertise and resourcing to manage the needs of such a patient group including the ongoing management of risks. The national drive is significantly to reduce the availability of specialist in-patient services for this group of patients but this must occur alongside an increase in both resources and expertise within community services.

Keywords - Community intellectual disability teams, Forensic services, Intellectual disability, Reconvictions, Reoffending, Transforming Care. 


\section{INTRODUCTION}

The availability of forensic services for people with intellectual disabilities (ID) varies across the UK in terms of patient group and levels of security (Chaplin and McCarthy, 2015). Although there is clear policy and guidance to what services should look like for the most complex cases ((Ministry of Justice 2009, Mansell et al. 2010), the provision of appropriate community based services for this group being discharged from secure hospital care is still aspirational in many areas of the UK. The Transforming Care agenda has put a focus on the reduction of inpatient services including secure services for people with ID following abuse of patients at Winterbourne View (Devapriam, et al., 2015). Due to the lack of local community and specialist service provision for those most vulnerable including offenders with ID, many people with ID are placed out of area so away from their local support networks(Chaplin et al. 2010). Many of the arguments put forward for not developing services locally such as community forensic services where there is clinical need is financial; given secure services operate as high cost, low volume services, which consume around a fifth of the NHS mental health budget (Fazel et al. 2016)

Within forensic services for people with ID there are three levels of security; low, medium and high in UK ((Royal College of Psychiatrists 2003)\& 04). The latter two are most likely to accommodate those with offending histories and the low secure services catering for those display offence type behaviours or who offend to a lesser degree. There is little research on the effectiveness of secure services and what there is can be difficult to compare as often clinical characteristics and client group can change over time as service structures and care pathways develop. Arguably the most comprehensive systematic review of long term effectiveness of forensic patients in secure care to date is Fazel et al (2016), who identified 35 studies from across the world with a total sample of 12056 and examined the following outcomes: mortality and suicide, readmissions and reoffending. Although ID services did appear in the selected papers, the authors did not present data specific to ID populations. There was wide variation in the 35 studies with the rates of prisoner reoffending were higher than in forensic psychiatric patients. Mortality rates were high amongst those discharged, with evidence to suggest that high rates were as a result of mental illness rather than being in a secure setting. The highest all-cause mortality rate was found in those sentenced to non-custodial sanctions, whereas those who had committed suicide were all people with a criminal justice history.

Although there has been an increase in studies of people with ID in secure services the evidence is still sparse. A long-term study which examined outcomes from an English regional medium secure unit over a 12-year period, 1987 to 1993 and 1994 to 2000 (Alexander, 
Crouch, Halstead, et al 2006), found patient characteristics of the two cohorts differed over time, with regard to where they were admitted from and the section used for detention, in spite of similar nature of index offences between the two groups. In terms of characteristics then personality disorder, a history of theft or burglary and young age have all been put forward as factors that increase the risk of reconviction (Alexander et al. 2006).

A 14 year evaluation of a UK national ID low secure mixed gender service in South East London (Reed, Russell, Xenitidis et al, 2004) (Reed et al. 2004) compared offenders ( $n=45$ ) i.e. detained under criminal sections of the MHA or on probation order during the admission $v$ non offenders $(n=41)$ i.e. detained under civil sections, and lacked a history of custodial sentences or previous high secure admission. The study found that there was a higher rate of personality disorder in the offender group, but there were no significant differences with regard to demographic and clinical characteristics profiles between the two groups, however the offenders group were less likely to be admitted from or discharged to the community. Therefore, there is no clear clinical characteristic that determine readmission and reoffending rates with the possible exception of presence of personality disorder.

The key issue with national policy is therefore is who can we safely discharge into the community and what support needs to be in place to reduce the risk of reoffending and readmission. The aim of this paper is to describe the characteristics of a group of patients discharged from an inner London secure hospital to see how successful the outcome what is terms of reoffending and reconviction for those discharged to the community.

\section{METHOD}

\section{Setting}

The study was set in a NHS Forensic service of a medium and low secure ward for men with intellectual disabilities in Hackney, an urban area in East London. The patients referred to the service tend to be from London and its surrounding areas so were relatively local to the service. This specialist service opened in June 2009. We included all patients admitted and discharged between this period and May 2016. The outcomes length of stay, readmission, reoffending on discharge were all defined as suitable outcome domains in a systematic review looking at the forensic ID group (Morrissey, Langdon, Alexander et al 2017). 
The aim of this service evaluation was to compare the following characteristics and outcome:

- nature of offences

- diagnoses and Co-morbidities

- length of stay

- discharge destination

- readmissions

- offending

\section{Participants}

All patients were male, aged between 18 and 65, and were admitted and discharged between 2009-2016. Overall there were 40 subjects included in the study; these comprised 29 patients admitted to medium secure and 11 admitted to low secure within the given time.

\section{Procedure}

The following patient characteristics were recorded: patients: age at time of admission; Mental Health Act status (Section the patient was detained under); index offence; past history of offending; level of intellectual disability; other diagnosed mental disorders; medication prescribed at time of admission and at discharge; length of stay (days); the destination of discharge or transfer; the community service under which the patient was discharged. We also looked at the outcomes of the patients following discharge; whether they had been readmitted or whether they had reoffended between the time of discharge and the point of data collection, and the characteristics of these patients.

Data was collected retrospectively from the patients' clinical notes, between SeptemberOctober 2015. Information which could not be found through this route was sought through contact with the patient's inpatient or community team whom they were discharged to.

\section{Analysis}

The data from the two levels of security was analysed separately, to identify possible differences in characteristics between the patients and their outcomes by level of security. Within the service, patients who are admitted to the medium secure ward are sometimes "stepped down" to the low secure ward when they are deemed of a lower risk at a later point in their 
admission. The level of security assigned to patient who moved within the service during their admission, is the level to which they were admitted originally.

\section{RESULTS}

\section{Demographics}

The average age of patients at time of admission to both services was 31.7. The average age of patients at time of admission to the low secure service was 34.2 and that of patients at time of admission to the medium secure service was 30.8 .

\section{Legal status}

Of the 40 patients, 28 (70\%) were detained under Part III of the Mental Health Act. $12(30 \%)$ were subject to Ministry of Justice restrictions; of these 9 (22.5\%) were under Hospital Orders with Restrictions (Section 37/41) and 3 were sentenced prisoners who were transferred (under Section 47/49). 11 of the 12 patients (91.7\%) who were subject to these restrictions were admitted to medium security. 14 were subject to hospital orders without restrictions (Section 37) and two were subject to an interim hospital order (Section 38). 12 of the 40 patients $(30 \%)$ were detained under "civil sections", eight of whom were admitted to medium security.

\section{Nature of offences}

The offences which led to the detention were $20(50 \%)$ patients had committed violent offences, 8 (20\%) sexual offences, 6 (15\%) arson offences, $5(12.5 \%)$ acquisitive, 2 (5\%) related to use or possession of weapons, 3 (7.5\%) harassment and hoax calls, 1 (2.5\%) property damage. Some patients had committed more than one offence; 9 had committed two offences in relation to this period of detention and 1 had committed three.

The patients' offending history was looked at. 15 (37.5\%) of the patients had an offending history of a similar nature to the index offence associated with this admission, $24(60 \%)$ of the patients had a history of offending which was of a different nature to the index offence, with $9(22.5 \%)$ patients having no previous offending history.

\section{Level of ID}

Of the 40 patients, 2 were found to not qualify for a diagnosis of intellectual disability after having undergone a period of assessment. The majority $(34,85 \%)$ were found to have a 
mild intellectual disability, $2(5 \%)$ were found to have a borderline intellectual disability and 2 $(5 \%)$ to have a moderate intellectual disability.

In terms of comorbid neurodevelopmental disorders $4(10 \%)$ of the patients had a diagnosis of Attention Deficit Hyperactivity Disorder (ADHD) (3 of which were placed in medium security) and 7 (17.5\%) had received a diagnosis of Autistic Spectrum Disorder (ASD), (6 of which were placed in medium security). In terms of mental health comorbidity, 14 of the 40 patients $(35 \%)$ had been diagnosed with a psychotic disorder, $14(35 \%)$ had been diagnosed with personality disorders, 5 of which had 2 or more personality disorder diagnoses. $8(57.1 \%)$ of those diagnosed with personality disorders had dissocial personality disorders, $1(7.7 \%)$ was diagnosed with psychopathic personality disorder and 6 (42.9\%) were diagnosed with emotionally unstable personality disorder. $11(27.5 \%)$ of the patients were noted to have diagnoses related to substance misuse.

\section{Length of stay}

The average length of stay for the 40 patients was 692.2 days. For the low secure patients, the average was 594.8 days and for the medium secure, 724.2 days.

\section{Discharge destination}

Twenty-seven (67.5\%) of the 40 patients were discharged into the community. Of these 27 patients, $22(81.5 \%)$ were discharged to supported living environments, one $(3.7 \%)$ to a probation hostel and four (14.8\%) to their family home. $3(7.5 \%)$ of the patients were transferred to a high secure hospital within the UK, all of which were from the medium secure ward and were transferred to the National High Secure Learning Disability Service (Rampton Hospital). Three (7.5\%) patients were transferred to "open" intellectual disability wards or another stepdown facility, two of which were from medium and one from low secure. Three medium secure patients were transferred to medium secure facilities outside of the service. Three $(7.5 \%)$ patients were transferred to prisons; two from medium security (see table 1).

\section{Insert table 1 around here}

\section{Discharge teams/service}

All 27 of the patients discharged to the community were discharged to community mental health teams. $14(53.8 \%)$ were discharged to Community Intellectual Disability Services 
(CIDS), $5(18.5 \%)$ were discharged to the care of general community mental health teams, 1 $(3.7 \%)$ was discharged to the care of joint-working, between a forensic community team and CIDS, $2(7.4 \%)$ were discharged to the care of joint-working, between general mental health team and CIDS and 4 (14.8\%) to community forensic teams. All of those discharged to jointworking teams were from medium security. Of the four discharged to the community forensic teams, three were from medium security.

\section{Readmissions}

Of the 40 patients, 27 were discharged to the community and 3 transferred back to prison. These 30 therefore had the potential to be readmitted within the time measured. Eight $(20 \%)$ were readmitted in this time, all from the community, one of whom was originally from low secure. Five of these patients were admitted to "open" learning disability wards, one was admitted to a Psychiatric Intensive Care Unit, one back to the medium secure specialist ward and 1 (the patient from low secure) was readmitted back to the low secure ward to which he was originally admitted. The time-lapse from date of discharge to readmission was on average 871 days. However, the patient readmitted to low security was readmitted 15 days following his discharge. The average time-lapse between date of discharge to readmission of the medium secure patients was 1002.9 days (see table 2 ).

Of the 8 who were readmitted $4(50 \%)$ had been under the community care of a CIDS, 1 $(12.5 \%)$ had been under the community care of a community forensic team, $1(12.5 \%)$ was under the joint care of a community forensic team and CIDS and $2(25 \%)$ was under the joint care of a general mental health team and a CIDS.

\section{Reoffending}

Of the 27 patients discharged to the community, six (22.2\%) had received further convictions between date of discharge and when the data was collected. One patient had been arrested, two patients had pending charges and 1 had been accused of an offence but had not yet been charged. The time-lapse between date of discharge and date of the reoffending behaviour was on average 904.4 days. 1 of these patients was from low secure; the time-lapse between discharge and this episode was 72 days. The average time-lapse for the remaining, medium secure patients was 997 days. Of the 10 patients who had (allegedly) exhibited 
reoffending behaviour, nine of the patients' (alleged) offending episodes were of a similar nature to that of their original offences. The patient whose alleged offending behaviour was different to that of the original offence was a medium secure patient who had been accused of sexual assault but had not yet been charged (see table 2).

Of the 6 who had received further convictions $3(50 \%)$ were under the care of CIDS, 1 was under the care of a community forensic team, 1 (16.7\%) was under the joint care of a community forensic team and CIDS and $1(16.7 \%)$ was under the joint care of a general mental health team and a CIDS.

All patients who had been readmitted or who had reoffended had been discharged 6 months or more at the time of conducting the study.

Insert table 2 around here

Insert table 3 around here

\section{DISCUSSION}

This study focused on a group of patients who had been admitted to an inpatient secure ID service, but also looked at their transition to the community and outcomes following that. The predominance of psychosis and personality disorder in the diagnostic make up reflect the complexity of the patient group within an inner London secure hospital.

This study has concentrated on length of stay (LoS), discharge destination and any future readmissions or reoffending activity. One of the difficulties in making comparisons of this type of study is a lack of agreed outcome measures and a minimum data set as put forward by the Royal College of Psychiatrists (2013). Other reasons why comparison with previous service evaluations is difficult, is that even within the same levels of security patient type, care pathways and treatment models may differ between services and areas. In terms of LoS previous research has shown a relationship between level of security and LoS, with those subject to high security having much longer admissions. Morrissey et al reported median LoS rates of 9,9 years in high security. In medium security reported LoS rates have been much lower and this current study shows a trend towards shorter admissions of under two years, which is lower than the 2.3 years and 2.8 from studies by (Alexander et al. 2011) . The trend to shorter length of stay implies that National Policy is having an impact ensuring secure inpatient services are focused on proactive discharge planning. It could also be ar- 
gued that this reduction in LoS may reflect the significant reduction in bed numbers for people with mental illness and learning disability (RCP, 2013), however given this reduction in inpatient resources it may be that those admitted will be more complex and so may be more likely to have longer than average admissions.

The latter point has become particularly relevant due to the push for people with ID to be cared for in the community, moving out of institutional care. The analysis of this patient group showed a high proportion with history of violent offending and under Ministry of Justice restrictions, therefore reflecting the severity of the offending behaviour and level of risk of those currently with in secure hospital acre. In this current study $28.2 \%$ of the patients were subject to a restriction order, however there is evidence from other studies that detention and restrictions imposed are subject to change over time as accepted practice changes as a result in shifts in national and local clinical policy and guidance (Alexander et al. 2006)). With regard to examining the nature of offences, making comparison can also be difficult given changes over time on how we treat offenders with ID. Historically rather than be processed through the Criminal Justice System, those whose behaviour would normally constitute an offence with ID and/or mental health problems may have just been diverted to hospital under a civil order. Also changes in the law e.g. new crimes such as cybercrime and changes in how we use the law will affect whether and what people will be charged with. An example of this can be seen in a community forensic sample where a trend to charge mothers with ID with abuse related offences against their children was noted (Wheeler et al 2009). This illustrates that it is likely that figures for some groups of ID offenders are inflated due to a lack of support from community services aimed at prevention.

When these patients were discharged, most commonly they were discharged under the care of the Community Intellectual Disability Service. A small number went under the care of a Community Forensic Team. Within the period examined, around a fifth reoffended and around the same proportion were readmitted. It is worth noting that almost two thirds of those readmitted were admitted to a unit of lesser security than they were previously discharged from, possibly reflecting a reduction in their risk following their inpatient treatment. Half of those who were readmitted and half of those who reoffended were under the sole care of CIDS in the community at the time. Given the complexity and risk associated with this group of patients it is important for the follow up in the community to be as robust as possible. Therein lies an argument for a specialist community forensic ID service, or at least a need for both aspects of their specialist needs (forensic and ID) to be met when they have been discharged to the community, to make the outcomes of this transition as successful as possible for them. This is probably the most critical part of National Policy that needs further investment to ensure the safe discharge of patients from secure services. 
Several hospital follow up studies have used the move to lower levels of security or supervision as an outcome measure (Alexander et al. 2011, Reed et al. 2004, Morrissey et al. 2007) However outcomes such as rates of recidivism or continued treatment success are highly variable due to vast differences in local provision and care pathways making any attempt to quantify long term effects of treatment received within secure inpatient settings. Another limitation aimed at studies of ID offender populations is that the samples reported on may not meet the criteria for ID. This also has implications for follow up as someone who meets the criteria for ID secure services may not be eligible for services on discharge to the community ID services with the scenario that no service will take responsibly for their care in the community. Although only two people were found to not to qualify for a diagnosis of intellectual disability in this current study, it is a contentious issue as although strict diagnostic criteria may not be met, they will all have clinically significant cognitive and social impairments.

\section{CONCLUSION}

Service evaluation studies are a barometer of practice and highlight the changing face of care for people with ID over time including those discharged secure hospital care, in part as a response to changing policy but also to an increased recognition of their complex needs of this group (McCarthy et al., 2016). This study illustrates that a complex group of patients with ID are being discharged to the community from secure hospital care with a significant number being readmitted or reoffending. There needs to be clear strategic thinking on how we can best deliver effective community based services for this group at risk of reoffending after discharge.

\section{ACKNOWLEDGEMENT}

We would like to acknowledge the support of Paul Gilluley at East London Foundation Trust for his help and support 


\section{REFERENCES}

Alexander, R., Hiremath, A., Chester, V., Green, F., Gunarantana, S. \& Hoare, S. (2011) Evaluation of treatment outcomes from a medium secure unit for people with intellectual disability. Advances in Mental Health and Intellectual Disabilities, 5(1), 22-32.

Alexander, R.T., Crouch, K., Halstead, S. \& Piachaud, J. (2006) Long-term outcome from a medium secure service for people with intellectual disability. J Intellect Disabil Res, 50(Pt 4), 305-15.

Alexander R, Devapriam J, Desari M, McCarthy J, Chester V, R Rahul, Naseem A \& Roy A (2015). "Why can't they be in the community?" A policy and practice analysis of transforming care for offenders with intellectual disability. Advances in Mental Health and Intellectual Disabilities, 9, 139-148.

Chaplin, E., Kelesidi, K., Emery, H., O'Hara, J., Lockett, J. \& McCarthy, J. (2010) People with learning disabilities placed out of area: The South London experience. Journal of Learning Disabilities and Offending Behaviour, 1(3), 5-14.

Chaplin E. \& McCarthy J. (2015) Offenders with Intellectual Disability in secure services and the criminal justice system. In Royal College of Psychiatrists Handbook of Secure Care (Eds: Dickens G, P Sugarman \& Picchiono M). Royal College of Psychiatrists Publications, London.

Chaplin E, Kelisdi K, Emery H, O'Hara J, Lockett J \& McCarthy, J. (2010). People with Learning Disabilities placed Out of Area - The South London Experience.Offending and Learning Disabilities Journal. 1, 3-14.

Devapriam, J., Rosenbach, A. and Alexander, R., 2015. In-patient services for people with intellectual disability and mental health or behavioural difficulties. BJPsych Advances, 21(2), pp.116-123.

Fazel, S., Fiminska, Z., Cocks, C. \& Coid, J. (2016) Patient outcomes following discharge from secure psychiatric hospitals: systematic review and meta-analysis. Br J Psychiatry, 208(1), 17-25. 
Mansell, J., Ritchie, F. \& Dyer, R. (2010) Health Service Inpatient Units for People with Intellectual Disabilities and Challenging Behaviour or Mental Health Problems. Journal of Applied Research in Intellectual Disabilities, no-no.

McCarthy J, Chaplin E, Underwood L, Forrester A, Hayward H, Sabet J, Young S, Asherson P, Mills R \& Murphy DM. (2016). Characteristics of prisoners with neurodevelopmental disorders and difficulties. Journal of Intellectual Disability Research. Doi: 10.1111/jir.12237

Ministry of Justice (2009) Lord Bradley's report on people with mental health problems or learning disabilities in the Criminal Justice System: The Government's response.

Morrissey C, Langdon P, Geach N, Chester V, Ferrister M, Lindsay W, McCarthy J, Devapriam J, Walker D, Duggan C, Alexander R (2017). A systematic review and synthesis of outcome domains for use within forensic services for people with intellectual disabilities. BJPsych Open. 3, 41-56.

Morrissey, C., Mooney, P., Hogue, T.E., Lindsay, W.R. \& Taylor, J.L. (2007) Predictive validity of the PCL-R for offenders with intellectual disability in a high security hospital: Treatment progress. Journal of Intellectual and Developmental Disability, 32(2), 125-133.

Reed, S., Russell, A., Xenitidis, K. \& Murphy, D.G.M. (2004) People with learning disabilities in a low secure in-patient unit: comparison of offenders and non-offenders. The British $j$ journal of psychiatry: the journal of mental science, 185(Table 1), 499-504.

Royal College of Psychiatrists (2003) Meeting the mental health needs of people with a mild learning disability, London, (Royal College of Psychiatrists Council report CR115).

Royal College of Psychiatrists (2013). People with learning disability and mental health, behavioural or forensic problems: the role of in-patient services. Faculty Report 03. July 2013. www.rcpsych.ac.uk 